\title{
NOTAS PARA UNA SOCIOLOGÍA DEL HOGAR NOTES FOR A DOMESTIC SOCIOLOGY
}

\author{
Fernando Sánchez Bravo-Villasante* \\ Universidad de Oviedo
}

\section{Resumen}

El artículo es un primer acercamiento a la sociología del hogar. Se hace una revisión sobre el concepto de hogar, que ha sido estudiado desde distintos ámbitos como grupo familiar, configuración de relaciones sociales, unidad económica y lugar de residencia, tratando algunas investigaciones relevantes. El hogar, entendido como lugar material de residencia y habitación, es un reflejo de la estructura económico-social en la que se inserta.

Palabras Clave: Hogar, familia, sociología del hogar.

\section{Abstract}

The paper is a first approach to the domestic sociology. It is a review of the concept of home, which has been studied from different angles such as family group, configuration of social relations, economic unit and place of residence, using some relevant research. The home, understood as a material place of residence and housing, is a reflection of the socio-economic structure in which it is inserted.

Keywords: Home, family, domestic sociology.

\section{Introducción}

El hogar es una institución fundamental para la descripción y comprensión de la vida social humana, así como para explicar su desarrollo a lo largo del tiempo. Como muchas otras instituciones sociales universales, su diversidad y variabilidad en las distintas culturas conocidas es inmensa, aunque en todas ellas conserva su función principal: servir de cálido alojamiento protector para la unidad social conviviente, generalmente basada en lazos de parentesco. Es pues 
en el hogar donde transcurren la mayor parte de las interacciones sociales típicas de las sociedades humanas, y donde más tiempo pasan los miembros de las sociedades, principalmente por su importante función de producción y consumo de servicios necesarios para el mantenimiento de la vida. El impacto del desarrollo económico y tecnológico ha tenido importantes consecuencias sobre las transformaciones que se han producido a lo largo de los siglos. Así mismo, la necesidad de adaptación al medio ecológico y la disponibilidad de recursos materiales para su construcción y mantenimiento, está en el origen de la enorme variedad de modelos existentes.

A pesar de su importancia social, la sociología no ha prestado mucha atención al estudio de los hogares hasta muy recientemente. Como muestra cabe citar que en la Enciclopedia Internacional de las Ciencias Sociales (1974), dirigida por David Sills, con colaboradores de más de treinta países, que fue uno de los últimos y más influyentes intentos en ofrecer un resumen teórico y metodológico de los principales avances en las disciplinas de antropología, ciencia política, derecho, economía, estadística, geografía, historia, psicología, psiquiatría y sociología hasta la primera mitad del siglo XX, no aparece una entrada para el término hogar. Y eso que es una publicación en once volúmenes y más de ocho millones de palabras ${ }^{1}$.

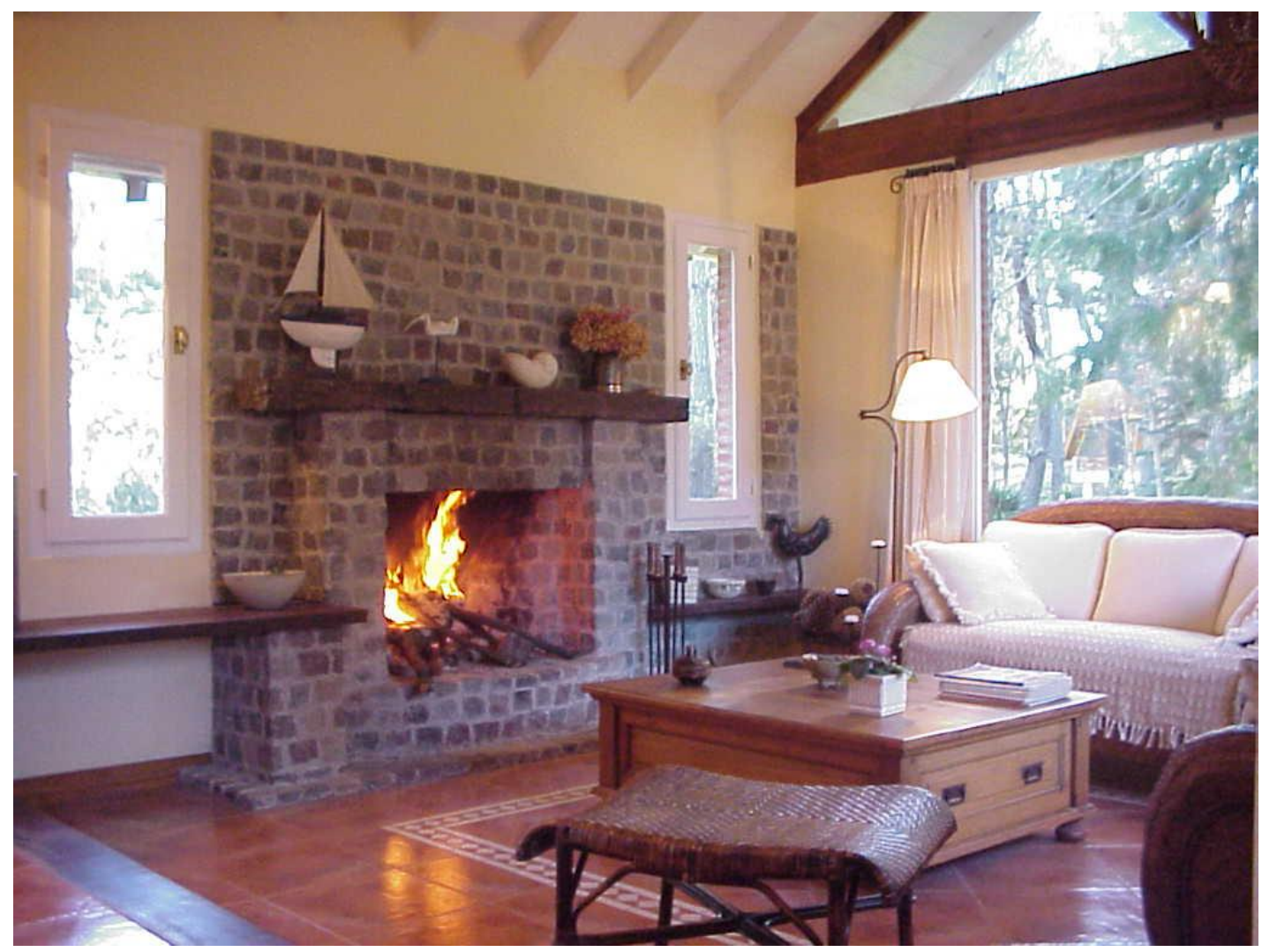

Fig.1. Interior de un hogar actual 


\section{Concepto de hogar}

Probablemente, la escasa atención de las ciencias sociales hacia la institución del hogar (quizás con la importante excepción de la antropología) tiene que ver con su papel fundamental para la vida privada, puesto que ésta se desarrolla principalmente en el ámbito íntimo de la casa o lugar de residencia. Durante sus inicios, ciencias como la economía, la ciencia política o la sociología se centraron más en el análisis de las actividades públicas desarrolladas por hombres: el hogar es el reino de la mujer, y como tal ha sufrido un cierto desprecio por parte de los padres fundadores, conservadores o radicales, que no ha sido resuelto hasta la reciente implantación de los estudios de género en el último medio siglo.

En el Diccionario de Sociología editado por Salvador Giner, Emilio Lamo de Espinosa y Cristóbal Torres ${ }^{2}$, aparecen dos entradas para el término hogar: la primera desde el punto de vista de la sociología general realizada por Inés Alberdi, y la segunda desde el punto de vista de la sociología económica, realizado por Mariano Fernández Enguita.

Para Inés Alberdi, el hogar es "la unidad de convivencia, el lugar donde se vive la intimidad, con la familia, y donde se desarrolla la vida privada. Hace referencia tanto al lugar donde se vive como a las personas que lo habitan formando una familia. Se identifica frecuentemente con vivienda, familia, forma de convivencia y lugar de residencia"3. Desde el punto de vista económico Fernández Enguita mantiene que "un hogar es un conjunto de personas que ponen en común sus recursos para la satisfacción de sus necesidades. En este sentido, no implica necesariamente parentesco ni cohabitación, aunque eso sea lo más común" 4

Con estas breves definiciones puede verse que el concepto de hogar es inherentemente polisémico: es tanto un lugar (de residencia), como un grupo social (las personas que conviven, generalmente con lazos de parentesco), como un conjunto de relaciones sociales (que lo convierten en institución establecida socialmente), como una estructura económica doméstica (para la satisfacción de necesidades a través de la producción y consumo de bienes y servicios). Su universalidad y su importancia social y económica, a pesar del inicial descuido con que fue tratado, hacen que hoy día sea objeto de múltiples líneas de investigación, tanto desde la historia y la demografía, como de la sociología y la economía.

\section{El hogar como grupo social}

Si nos referimos al hogar como las personas que lo integran, sucede que inmediatamente tiende a confundirse con la familia, puesto que tradicionalmente la mayor parte de los hogares han estado formados por familias, es decir por personas relacionadas por vínculos de parentesco y consanguinidad adscritos por herencia, o adquiridos a través del matrimonio, que ha sido la institución social 
preferentemente utilizada en todas las culturas conocidas para la formación de nuevas familias. Alberdi advierte que "no conviene identificar hogares con familias de manera automática, como se hace frecuentemente en el lenguaje vulgar. Las personas que integran un hogar, como unidad económica de convivencia, configuran una unidad familiar, pero muchas personas que pertenecen a una misma familia no comparten el mismo hogar"5.

Si somos humanos es porque reconocemos los lazos biológicos del parentesco y la descendencia, a diferencia del resto de los animales, en los que dichos lazos se olvidan después de la lactancia y crianza de los vástagos. Para Freud la primera norma humana, fuente de todas las demás, es el tabú del incesto, que es el origen de las familias, al prohibir que el macho alfa dominante tenga el monopolio sexual de las hembras, obligando a establecer reglas de parentesco, cuyo fin principal, es determinar un mercado matrimonial. El grupo familiar se convierte así en la célula originaria de toda organización social posterior, que la toma como modelo, y que a través del proceso de diferenciación ${ }^{6}$, es el origen de las principales instituciones sociales fundamentales: estado, empresa, religión, educación, sanidad, etc.

Conviene no confundir hogar con familia, puesto que son dos realidades distintas aunque íntimamente relacionadas. Si consideramos las sociedades tradicionales preindustriales, fundamentalmente rurales y agrarias, se puede decir que la unidad social básica es la familia, tanto a efectos políticos, como sociales, económicos y culturales. Eran sociedades escasamente meritocráticas, en donde la posición del individuo en la estructura social venía dada sobre todo por el nacimiento, y donde poco podía hacerse para cambiar la situación inicial de género, esclavitud, servidumbre o nobleza, donde no había igualdad ante la ley, los derechos eran prácticamente inexistentes, y la vida individual estaba sometida a innumerables deberes y obligaciones, especialmente impuestos por figuras masculinas dominantes, como el pater familias.

No será hasta el Renacimiento y la Ilustración, fenómenos característicamente europeos, que se iniciará el camino hacia la liberación de las antiguas estructuras dominantes. Para Burkhardt el renacimiento y el humanismo, primero en Italia, y luego en el resto de Europa, suponen el origen del individuo como sujeto histórico, sin el cual habría sido imposible la Ilustración, el desarrollo científico, la revolución industrial y el estado liberal7. T.H. Marshall 8 ha analizado el desarrollo de los modernos derechos de ciudadanía (civiles, políticos y sociales) desde el siglo XVIII hasta el XX, basándose en el caso inglés, que tienen como sujeto al individuo libre como portador y garantía de los mismos, antes que a las familias o los distintos grupos de status sociales tradicionales.

El proceso de modernización acaecido en los últimos siglos ha traído consigo una radical transformación de la estructura de las familias, que ha tenido consecuencias en el funcionamiento de los hogares. Puede citarse la creciente tendencia a la disminución del tamaño de los hogares, sobre todo debido al aumento de personas que viven solas, ya sea por el aumento de la esperanza de vida y consiguientemente de las situaciones de viudedad, ya sea por elecciones 
personales. Según los datos censales [www.ine.es], el tamaño medio del hogar en España ha pasado de ser 3,2 personas según el censo de 1991, a 2,9 en el de 2001, y a 2,6 en el de $2011^{9}$.

El aumento de los hogares unipersonales representa un cambio social importantísimo, puesto que actualmente en España ya hay más de tres millones de hogares unipersonales, que representan aproximadamente una quinta parte del total.

\section{El hogar como conjunto de relaciones sociales}

Si un hogar está formado por un grupo de personas, sociológicamente puede ser considerado como un conjunto de relaciones sociales. Esto es lo que le convierte en una institución social, quizás la más antigua, junto a la familia, a la que tradicionalmente ha estado unido. La tendencia al crecimiento de los hogares unipersonales, característicos de las ricas sociedades posmodernas, pone en cuestión este significado, pero ello no obsta para considerar su relevante papel histórico como núcleo fundamental de la sociabilidad humana.

Este es el punto de vista adoptado por Norbert Elias en su obra El proceso de la civilización: investigaciones sociogenéticas y psicogenéticas, en la que se propone investigar cuales fueron las causas del desarrollo de la civilización occidental $^{10}$. Es, por tanto, un estudio del cambio social, pero basándose en las lentas transformaciones de las estructuras de la personalidad y la sociedad en Europa desde el mundo guerrero medieval hasta el proyecto moderno de la Ilustración. El ambicioso proyecto estaba emparentado con el interés de los autores de la escuela de Frankfurt en el fracaso de la modernidad al hilo de los violentos acontecimientos de la primera mitad del siglo XX.

El libro se divide en tres capítulos y un resumen final con el título de Bosquejo de una teoría de la civilización. El segundo se llama La "civilización" como transformación específica del comportamiento humano, y en él realiza un detallado análisis de los cambios principales que ha experimentado la conducta de los europeos a lo largo de esos siglos para cristalizar en el hombre ilustrado del siglo XVIII, como uno de los actores principales del proceso de civilización occidental, aún no concluido. Su trabajo, con influencias de Marx, Weber y Freud, coincide con el punto de vista de este último en su Malestar en la cultura ${ }^{11}$ acerca de que el ser humano ha de pagar un importante precio para convertirse en culto y civilizado: la represión de sus instintos más naturales mediante el control de su comportamiento, tanto en la esfera pública como en la privada.

Frente al ensayo freudiano, Elias utiliza una metodología enormemente original, que consiste en el análisis textual de los manuales dirigidos a los hombres y mujeres de las épocas estudiadas para la formación del carácter, a través del énfasis en los buenos modales de los caballeros y las damas ${ }^{12}$. Comienza con el concepto medieval de cortesía, que encarna el ideal del buen comportamiento, y que es promovido en primer lugar para la nobleza. Después prosigue con el estudio de una obra de Erasmo de Rotterdam, que tuvo un gran 
impacto, pues tuvo más de treinta ediciones en distintos idiomas en vida del autor y que lleva por título De civilitate morum puerilium. El contenido de la obra se refiere a la conducta de las personas en sociedad y está escrito en forma de consejos y recomendaciones al hijo de un príncipe.

Los siguientes epígrafes del capítulo llevan los siguientes títulos: la compostura en la mesa, cambios en las actitudes frente a las necesidades naturales, sobre el modo de sonarse, sobre el modo de escupir, el comportamiento en el dormitorio, cambios en la actitud frente a las relaciones entre hombres y mujeres, y las transformaciones de la agresividad. Como puede apreciarse, todo este análisis se refiere a las relaciones sociales, y su aprendizaje debe ser realizado preferentemente en el hogar, constituyendo toda una serie de normas y reglas sobre las interacciones que se producen en el seno del mismo.

Los procesos civilizatorios de construcción de los estados nación, de división del trabajo y de diferenciación de funciones, de expansión de las ciudades y la industria aumentan exponencialmente el número e intensidad de las relaciones sociales. Concluye Elias:

"al aumentar los grupos de personas en relaciones de interdependencia y al excluirse de éstas los actos de violencia física, surge un aparato social en el que las coacciones que los hombres ejercen unos sobre otros se transforman en autocoacciones; estas autocoacciones, que son funciones de una previsión y reflexión permanentes que se inculcan en el individuo desde pequeño en correspondencia con su imbricación en secuencias más largas de acciones, tienen parcialmente la forma de un autodominio consciente, parcialmente también la forma de costumbres, y funcionan de modo automático. Su resultado es una contención regular de las manifestaciones instintivas y emocionales, según un esquema diferenciado peculiar a cada situación social"13.

Para Elias, no es posible comprender el proceso civilizatorio como algo impuesto por la fuerza por las elites, o clases dirigentes para mantener sus privilegios, su poder y su posición social. Para que se produzca es necesario también un impulso de abajo arriba, mediante el autocontrol y dominio del comportamiento individual en situaciones sociales, pues es ahí donde residen las oportunidades de participar en la distribución de poder, influencias y riquezas. Y esto se aprende mediante la interiorización de códigos de conducta, especialmente a través de la socialización en la vida familiar dentro del hogar.

El hogar constituye una configuración de relaciones sociales, que se transmiten de padres a hijos, que está establecida socialmente y que es indispensable para el éxito del proceso civilizatorio. El análisis de Elias muestra que dicha configuración es cambiante, ya que debe adaptarse a las distintas necesidades de cada tipo de sociedad, pero que es un elemento primordial para explicar el desarrollo económico, político, social y cultural occidental. 


\section{El hogar como unidad económica}

Según Fernández Enguita "el hogar es el ámbito y la estructura de lo que podemos llamar el modo de producción y distribución doméstico, un conjunto de relaciones con su propia lógica que ha antecedido y acompañado a todas las formas económicas posteriores [...] En cualquier economía avanzada, la mitad del tiempo de trabajo y todo el consumo final tienen su escenario en los hogares (incluidos los unipersonales), lo que hace inexcusable su consideración"14.

Nuevamente se encuentra aquí la variedad de significados que se pueden atribuir al hogar: ámbito, estructura, modo de producción, conjunto de relaciones. Su importancia económica no puede ser menospreciada, como cuando los clásicos definían al trabajo doméstico como no productivo porque no se insertaba en las relaciones de producción capitalista, no producía para el mercado, y por tanto no generaba plusvalía. Los análisis de género impulsados por el movimiento feminista han producido una gran cantidad de investigaciones que muestran a los hogares y familias como un elemento indispensable para la discriminación de género desde hace siglos. En el reciente manual sobre Sociología y género, editado por Capitolina Díaz y Sandra Dema ${ }^{15}$, en el capítulo sobre familias, escrito por Marie Withers Osmond y Barrie Thorne ${ }^{16}$, se realiza una revisión de los distintos enfoques sobre sociología de la familia. Hasta mediados del siglo XX, el punto de vista predominante ha sido el estructural funcionalista, derivado de las aportaciones de Talcott Parsons ${ }^{17}$, que se basa en la consideración de la familia nuclear, formada por el matrimonio y sus hijos, en la que se da una clara división de roles entre el padre como sustentador principal a través de su empleo asalariado, y la madre como encargada del mantenimiento del hogar y de la crianza de los hijos.

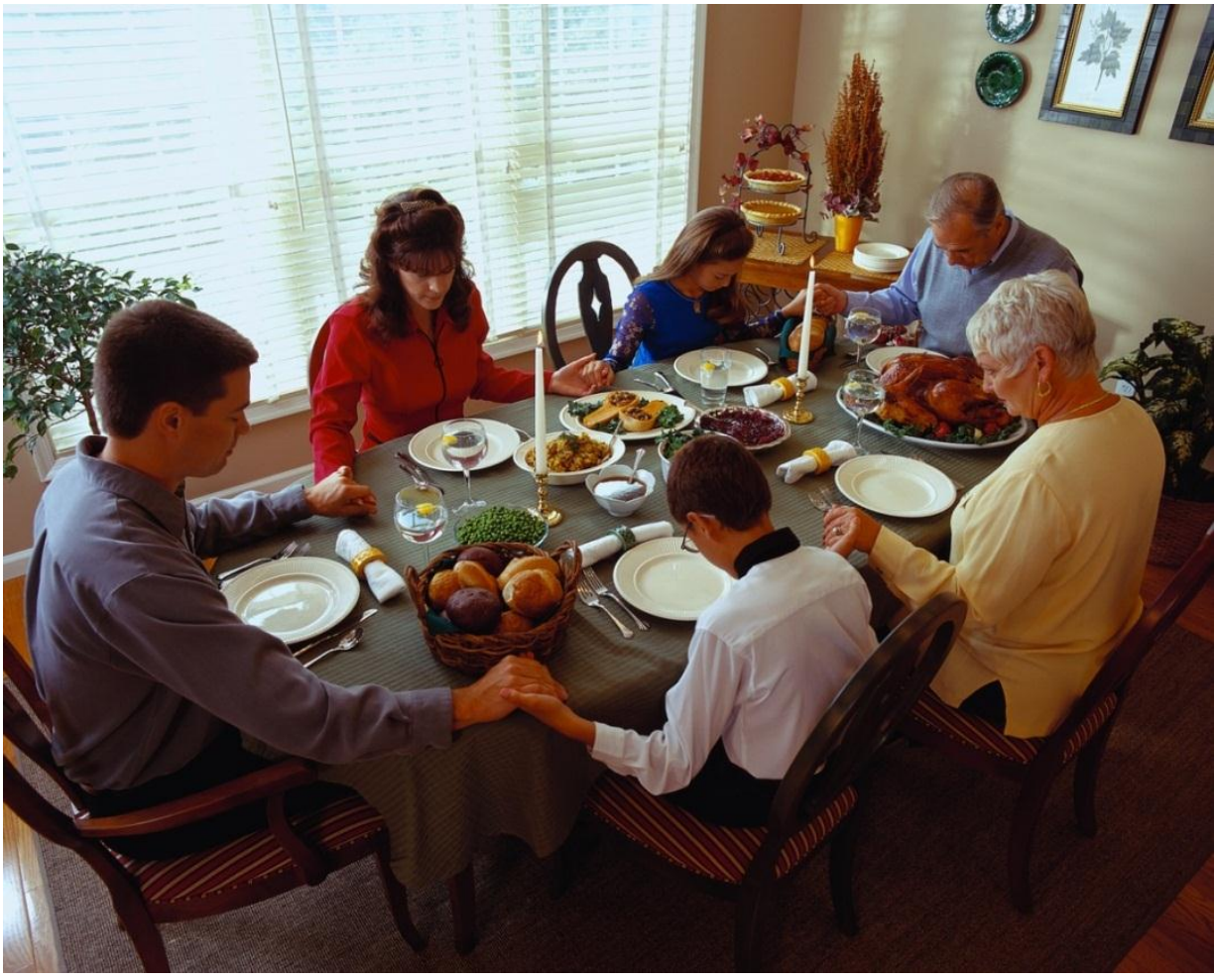

Fig. 2. El comedor funciona como un punto de encuentro familiar diario alrededor de la comida. 
La masiva incorporación de la mujer al empleo remunerado fuera del hogar en la mayoría de los países durante las últimas décadas ha vuelto obsoleto este enfoque: por ejemplo, hoy día hay más mujeres que hombres en el mercado de trabajo de Estados Unidos. El proceso de igualación de género en todos los ámbitos de la vida pública ha sido uno de los cambios sociales más importantes de todo el siglo XX, y ha producido consecuencias inevitables en la estructura y configuración de los hogares modernos, hasta el punto de que el modelo de hogares formados por familias nucleares como las que describe la teoría funcionalista ha pasado a ser minoritario en la mayor parte de las economías desarrolladas, tal y como muestran los datos censales [www.eurostat.eu].

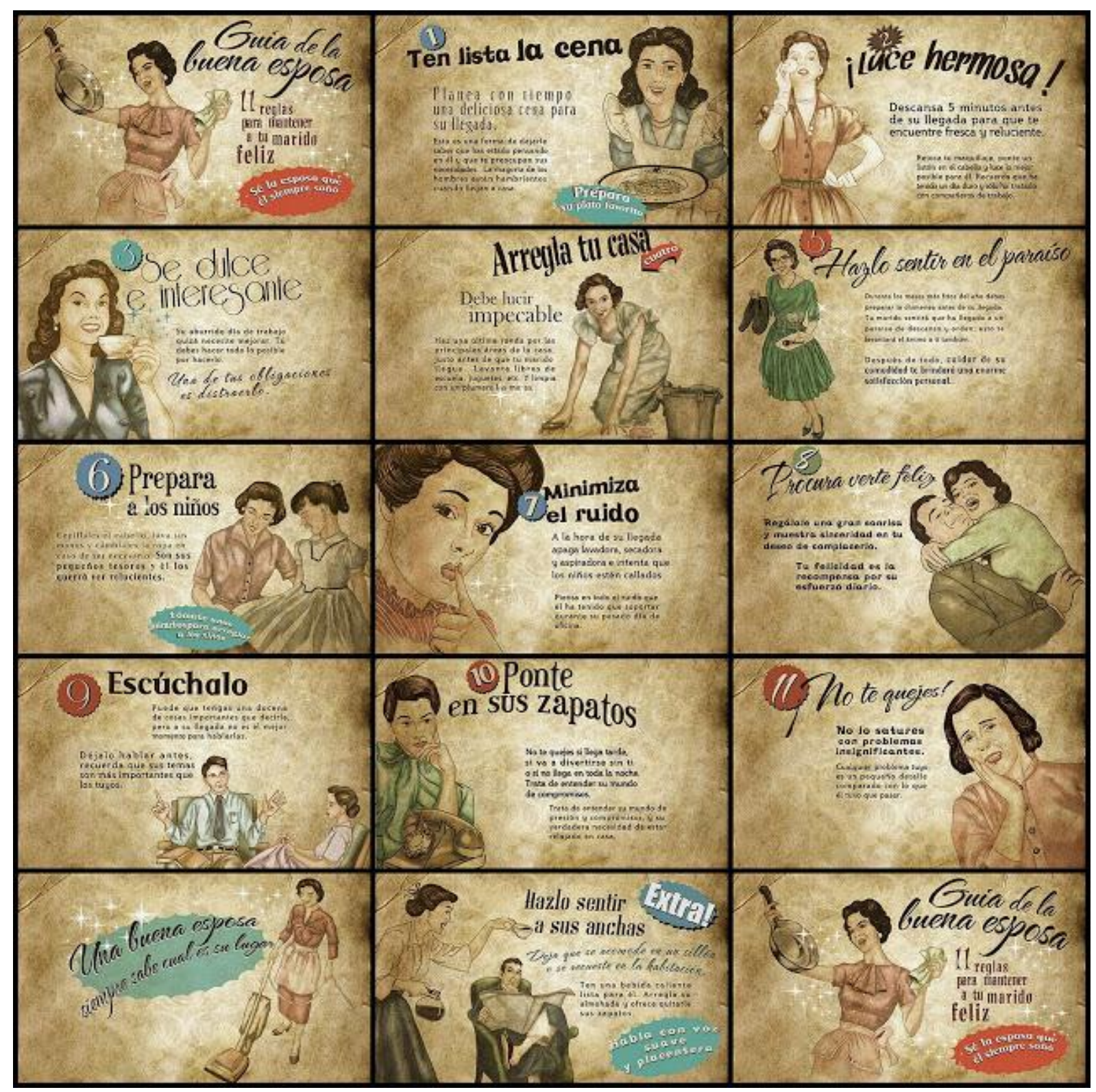

Fig. 3. Publicidad de la Sección Femenina durante el Franquismo 
El empleo de la mujer fuera del hogar ya no es en muchos casos un complemento al salario del marido, sino que se convierte en un fenómeno clave para la emancipación de las mujeres frente la dependencia del varón. En España ya son más numerosas las estudiantes universitarias que los estudiantes, mostrando una clara intención de insertarse en los complejos mercados de trabajo actuales. Esto ha tenido efectos sobre la forma, estructura y funciones de los hogares: reducción del número de miembros, disminución de las tasas de natalidad, aumento de los divorcios y de los hogares unipersonales y monoparentales (generalmente constituidos por mujeres solas y sus hijos) [www.ine.es].

La preeminencia de los análisis funcionalistas (la familia nuclear es funcional para la sociedad con su división de roles y tareas) y marxistas (la familia nuclear es un producto de la desigual estructura de clases capitalista), ha sido puesta en cuestión por los análisis de género, cuya aplicación introduce nuevas vías de investigación y aclara muchos de los supuestos tácitos de los anteriores enfoques. Para Osmond y Thorne ${ }^{18}$ :

"las cuestiones de género se hallan en el núcleo de la conceptualización de la familia. Cambiar la preocupación por los dualismos (los hombres frente a las mujeres, lo público frente a lo privado) por una conceptualización de las relaciones de género a distintos niveles (personal organizativo y simbólico) es un gran paso adelante. Si examinamos las relaciones de género en relación con otros elementos diferenciadores y teniendo en cuenta otras desigualdades como las de clase social, raza, etnia, sexualidad y edad se logra una comprensión más profunda de la realidad. Las visiones feministas no solo añaden nuevos temas a los estudios de la familia sino que remodelan profundamente los modos básicos de entender las familias y los hogares y sus interconexiones con la sociedad".

El acercamiento de género a las cuestiones de hogares y familias representa un avance considerable sobre los tratamientos tradicionales, poniendo el énfasis en las relaciones de poder y género entre los habitantes del hogar.

Volviendo al análisis del hogar como unidad económica, es indudable la importancia del mismo como señala Fernández Enguita, aunque sea dudoso afirmar que todo el consumo final tiene lugar en los hogares, pues el importante desarrollo de las industrias turística y del viaje desde mediados de los años cincuenta, con cerca de mil millones de desplazamientos internacionales anuales solo en avión (según datos de la Organización Mundial de Turismo, www.omt.org), hacen que gran parte del consumo de bienes y servicios tengan lugar fuera del hogar, aparte del que realizan las empresas y otras organizaciones.

En todo caso, las funciones económicas de los hogares han sufrido enormes variaciones a los largo de los últimos siglos. En las sociedades tradicionales agrarias, anteriores a la revolución industrial, el hogar no sólo era una unidad de convivencia sino principalmente una unidad de producción. La mayor parte de la población era rural, y vivía en pequeños núcleos campesinos, cerca de las tierras que trabajaban, entre otras cosas por la inexistencia de los medios de transporte 
modernos que facilitan la movilidad. La casa campesina y la urbana, con múltiples variedades regionales y locales, ha sido estudiada por Raffaella Sarti en su Vita di casa: abitare, mangiare, vestire nella Europa moderna (2008), en el que realiza un análisis de los diferentes tipos de hogares existentes en los países europeos entre los siglos XV y XIX, centrándose como indica el subtítulo en la vida material de las familias y sus transformaciones durante ese período, a través del uso de múltiples fuentes documentales. Es interesante anotar que la historiadora italiana ha llegado a este campo de estudio partiendo de sus trabajos sobre la historia de las mujeres.

El hogar campesino preindustrial es básicamente una organización productiva agraria, en donde la economía está mucho menos mercantilizada, y la mayor parte de la producción es para el autoconsumo. El trabajo asalariado está mucho menos extendido, excepto los jornaleros en las épocas de recolección de las cosechas, y las familias más o menos extensas que cohabitan en la casa trabajan juntas bajo la dirección del pater familias (padre patrón) para obtener los recursos necesarios para la subsistencia en condiciones penosas y exigentes. El fatalismo y la resignación imperantes son consecuencia de que los resultados productivos no dependen únicamente del esfuerzo empleado, sino también de factores escasamente controlables como la meteorología, o las frecuentes guerras y conflictos armados.

La industrialización transformará radicalmente este estado de cosas, en primer lugar a través de la creciente importancia de las ciudades, de los procesos de urbanización que inevitablemente se producen por la centralización de las actividades industriales y mercantiles en determinadas zonas geográficas. La emigración del campo a la ciudad es consecuencia directa del proceso, y el último ejemplo al respecto lo tenemos en los importantes movimientos de población y de urbanización que se han producido en China en las últimas décadas, acompañando a su proceso de crecimiento económico.

Los nuevos hogares urbanos tienden a ser viviendas en altura, cercanas a las fábricas, y de tamaño mucho más reducido que las campesinas. Esto produce el auge de la familia nuclear y el inicio de la disminución del tamaño de los hogares. Las condiciones deplorables de habitabilidad de los primeros asentamientos obreros irán dando paso a mejoras importantes mediante la construcción de infraestructuras más modernas, que a partir de finales del siglo XIX irán generalizando el uso de la electricidad, el tratamiento de las aguas, la mejora en los transportes y el uso del automóvil. El período de crecimiento económico posterior a la II Guerra Mundial, con la expansión de los estados de bienestar europeos y la sociedad de consumo de masas, significa también la industrialización del hogar, con la aparición y multiplicación de los electrodomésticos (línea blanca de la cocina, línea oscura del salón, donde la televisión se convierte en un nuevo polo de atracción de las relaciones domésticas).

Dado que el empleo asalariado significa trabajar fuera del hogar, éste pierde importancia como unidad productiva, a la vez que la gana como unidad de consumo, de residencia y emocional, que son las funciones que predominan en la 
actualidad. La industrialización del hogar permite que las tareas domésticas sean menos intensivas, y que las mujeres dispongan de mayor tiempo, facilitándoles su incorporación al mercado de trabajo externo. Aun así, la persistencia de lo que se denomina la doble jornada, es decir que las mujeres que trabajan fuera de casa, siguen ocupándose mayoritariamente de las tareas domésticas ${ }^{19}$ manifiesta que el hogar sigue siendo en muchos casos el último reducto de la desigualdad de género.

\section{El hogar como lugar de residencia}

Finalmente, el hogar es también un lugar de habitación: donde viven los humanos. De hecho, esta es su concepción original, pues etimológicamente el término hogar proviene de fuego, y así lo recoge en su primera acepción el Diccionario de la RAE: "sitio donde se hace la lumbre en las cocinas, chimeneas, hornos de fundición, etc." Además también recoge otras dos acepciones: casa o domicilio; familia, grupo de personas emparentadas que viven juntas. El hogar era el centro de las viviendas en las sociedades tradicionales, cuando aún no se disponía de energía eléctrica ni de sofisticados electrodomésticos ${ }^{20}$.

El hogar es también una realidad material: el lugar donde habitan las familias, incluyendo todos los objetos necesarios para hacer la vida más acogedora y conveniente. Tradicionalmente ha sido considerado como un lugar femenino, puesto que ofrece calor, protección y cobijo frente a las inclemencias del tiempo y de la vida en la naturaleza, especialmente para los más dependientes: niños, ancianos, enfermos. La casa, el hogar familiar, es el lugar donde los humanos solemos pasar la mayor parte del tiempo en general, pues es donde descansamos, dormimos, amamos, comemos y nos relacionamos con nuestros allegados más próximos en el tiempo libre después de las obligaciones laborales.

Tiempo libre no es equivalente a ocio, pues precisamente para que la casa funcione correctamente, necesita una gran cantidad de producción de bienes y servicios domésticos, que han sido realizados fundamentalmente por las mujeres: comprar, cocinar, limpiar, lavar, planchar, cuidar, ordenar, guardar etc. Una característica de la actividad doméstica es su carácter interminable y recurrente, puesto que la mayor parte se consume inmediatamente sin dejar rastro, lo que obliga a su producción continua, independientemente de fiestas, jornadas laborales, jubilaciones o vacaciones. Dado que esta producción sin fin no está monetarizada, su importancia económica ha sido desatendida por la ciencia económica académica, que hasta hace poco tiempo solo se interesaba por las economías de mercado.

La investigación sobre el papel económico de las mujeres es ya muy relevante, originada por el enfoque feminista. En España una de las pioneras ha sido María Ángeles Durán, que ha estudiado sistemáticamente la importancia del trabajo de las mujeres, tanto en el ámbito doméstico, como en la economía mercantil. En uno de sus últimos trabajos recuerda que "en cuanto a la economía, poca gente, incluidos los economistas recuerda su origen. Viene del griego oikos, 
que significa hogar"21. No es casual que el ministerio que se ocupa de los impuestos y su recaudación sea el de "hacienda".

Volviendo a los hogares como lugares de residencia, conviene apuntar su relevancia económica: la burbuja inmobiliaria que está detrás de la actual crisis económica mundial se origina en parte por un desmesurado crecimiento de la actividad constructiva de viviendas en diversos países, que ha dejado una gran cantidad de las mismas vacías y sin vender (unas 800.000 en el caso español), y cuya financiación a través de préstamos a constructoras y potenciales clientes está en la base del actual desastre financiero. No conviene pensar que el hogar es un lugar fijo de habitación: Raffaella Sarti nos recuerda que:

"Hablando de casas del pasado todavía es necesario habituarse a no imaginar necesariamente construcciones sólidas con puertas y ventanas. Entre el que duerme bajo las estrellas y el que vive en un palacio existe toda una variedad de situaciones intermedias... El mismo límite inferior del concepto de casa es muy vago: ¿qué decir de los que habitan en precarias cabañas vegetales? ¿O de los pescadores del Báltico y del litoral francés de la Mancha que viven en viejas barcas acondicionadas? El continuo entre los que tienen un techo sobre la cabeza y quienes no lo tienen es más bien lábil. Si entonces, como justamente se ha escrito, la historia de la casa no debe ignorar a los sin techo y vagabundos, no puede tampoco ignorar toda esta vasta gama de viviendas y refugios" 22

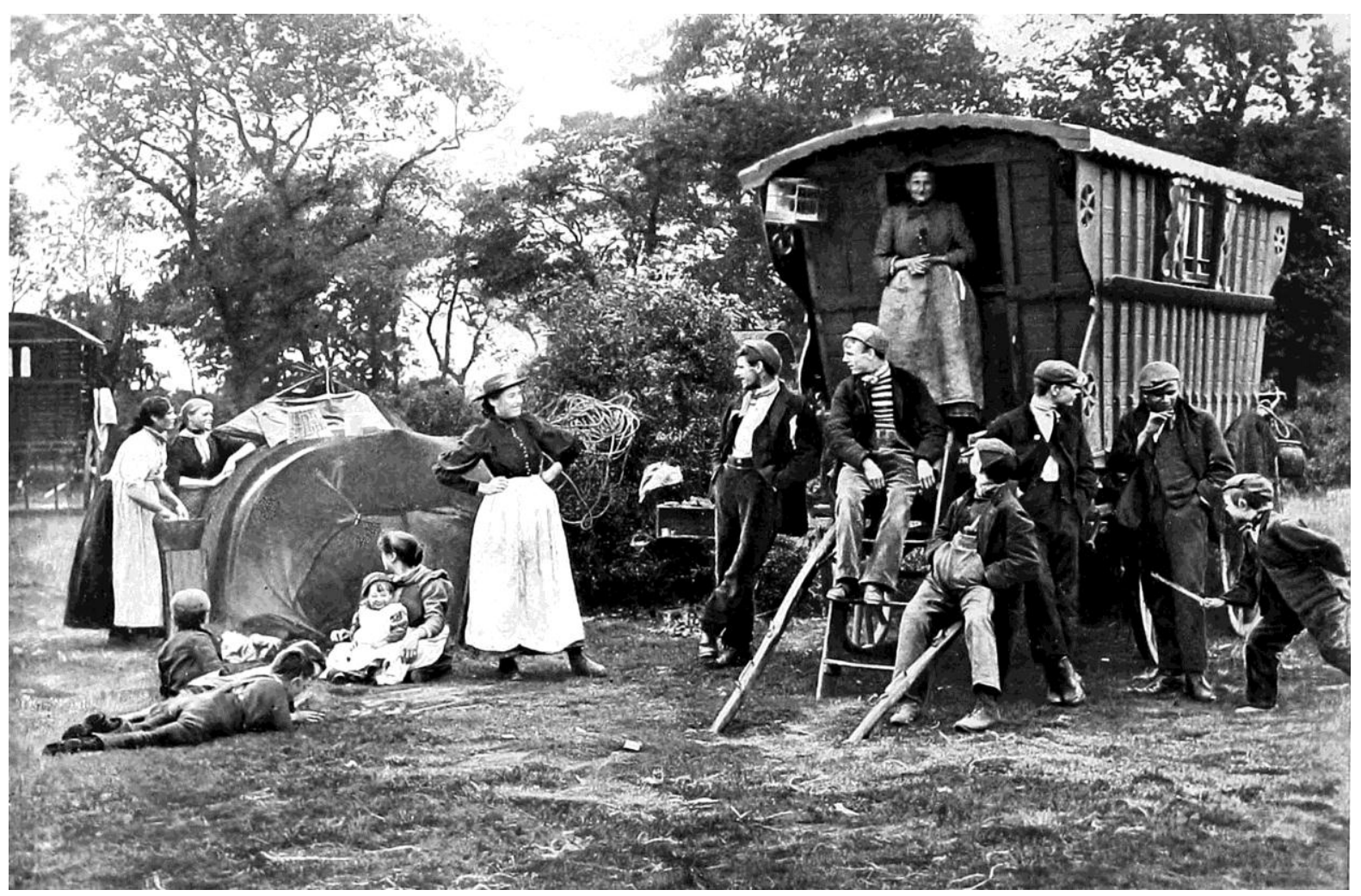

Fig. 4. A gipsy encampment in Essex The Queen's Empire. Volume 1. Cassell \& Co., London. 1897-1899. 
De hecho, el origen del hogar, como su propio nombre nos indica, es el fuego alrededor del que se reunían las primeras sociedades humanas nómadas de cazadores y recolectores, buscando calor, cocina y protección frente a los animales predadores. El hogar original es pues móvil, y está donde se enciende la hoguera benefactora, al aire libre o en refugios naturales. Ese es el origen de la socialidad humana durante miles de años, y si la movilidad es un requisito indispensable, ello no obsta a que ya aparezcan elementos materiales (armas, utensilios de cocina, tejidos, calzados, en general muy ligeros para poder ser transportados) que son el origen del mobiliario hogareño moderno.

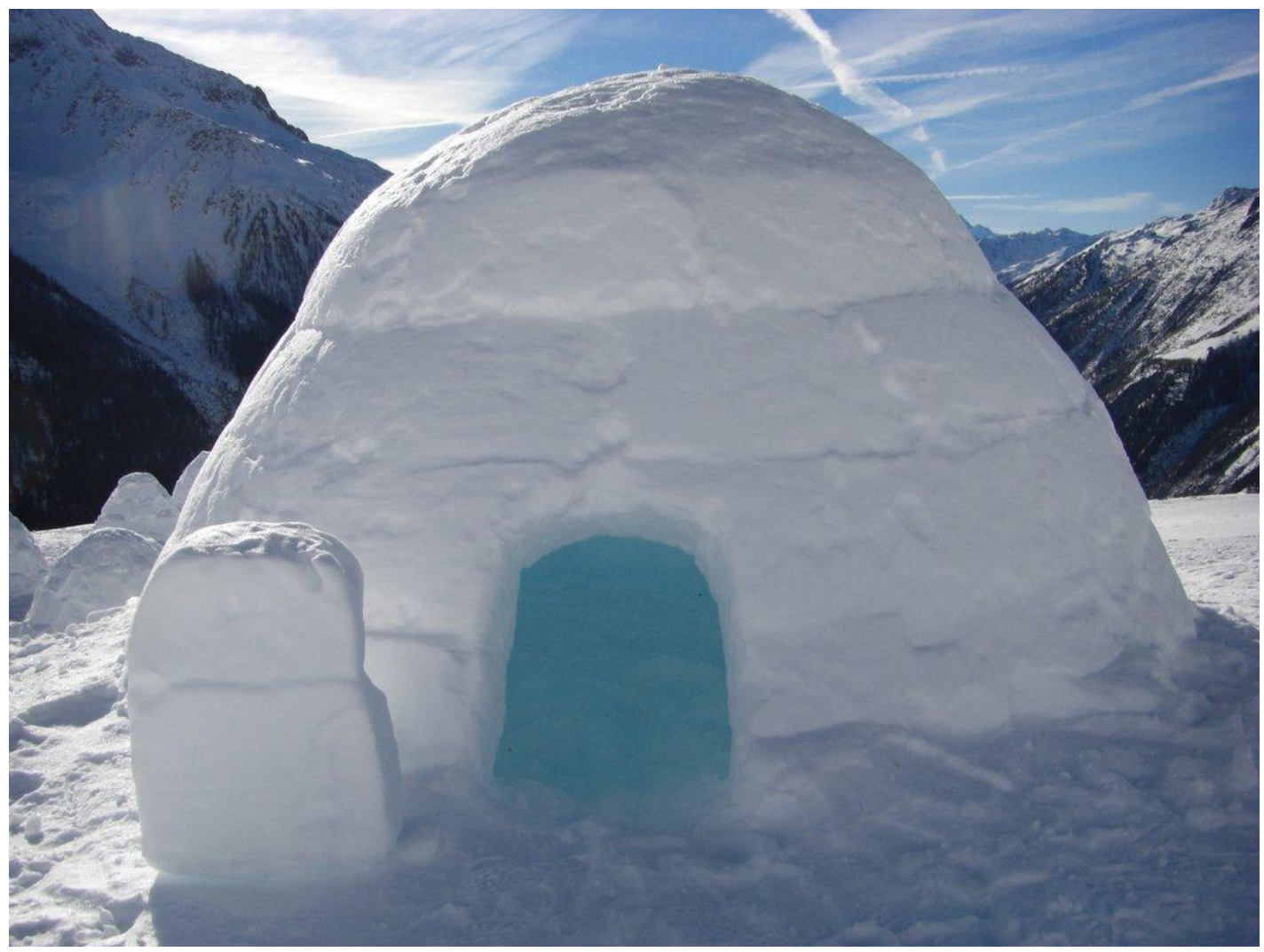

Fig. 5. Iglú como vivienda adaptada el medio.

El hogar-vivienda moderno ha multiplicado sus variedades: estudio, apartamento, piso, dúplex, ático, adosado, pareado, chalet, mansión, palacio etc. A lo largo del tiempo su realidad material ha influido decisivamente tanto en la arquitectura y la construcción, como en el amueblamiento interno para facilitar la vida de sus habitantes y permitirles desarrollar sus funciones de la mejor manera posible. Una característica importante, tanto de las casas agrícolas tradicionales (villas, caserías, masías, cortijos, haciendas, ranchos, etc.) como de las viviendas modernas es que los objetos materiales que conforman el hogar deben ser a la vez útiles (para cumplir su función) como estéticamente bellos (tanto para la satisfacción de sus propietarios como para su exhibición como símbolos de status). 
El amueblamiento interior de las casas es uno de los motores más importantes de la demanda de objetos, ya sean realizados artesanalmente por los propios moradores, o adquiridos en el mercado, como sucede en la actualidad. La necesidad de rodearse de instrumentos útiles para la producción de servicios en las economías domésticas es continua en las viviendas de todas las épocas, y más teniendo en cuenta su obsolescencia causada por el uso.

El gusto por rodearse de cosas bellas en la vivienda, independientemente del nivel socioeconómico, ha generado una constante producción no solo de edificios residenciales, sino también de su amueblamiento interior para cumplir las múltiples funciones del hogar: descanso, alimentación, protección frente a los rigores del clima y la naturaleza. Sociológicamente hay otra función no menos importante que tienen las viviendas: la exhibición de status. De ahí la separación entre las habitaciones más privadas (dormitorios, cocinas, baños) y las más públicas, orientadas a reuniones sociales con familiares, amigos o invitados (comedores, salones y demás).

Puede considerarse que la vivienda es, junto con los templos religiosos, las construcciones para la sede del poder y más recientemente las empresas, uno de los impulsores principales de la demanda de objetos artísticos, sean o no funcionales: muebles, vajillas, mantelerías, ropa de cama, pinturas, cerámicas, cristalerías, etc. El grado de desarrollo económico influye decisivamente sobre la producción artística y su calidad, pero el criterio estético no es patrimonio de las clases altas, como muestran fehacientemente los museos arqueológicos, antropológicos y etnográficos (por ejemplo el del Museo de Grandas de Salime en Asturias $^{23}$.

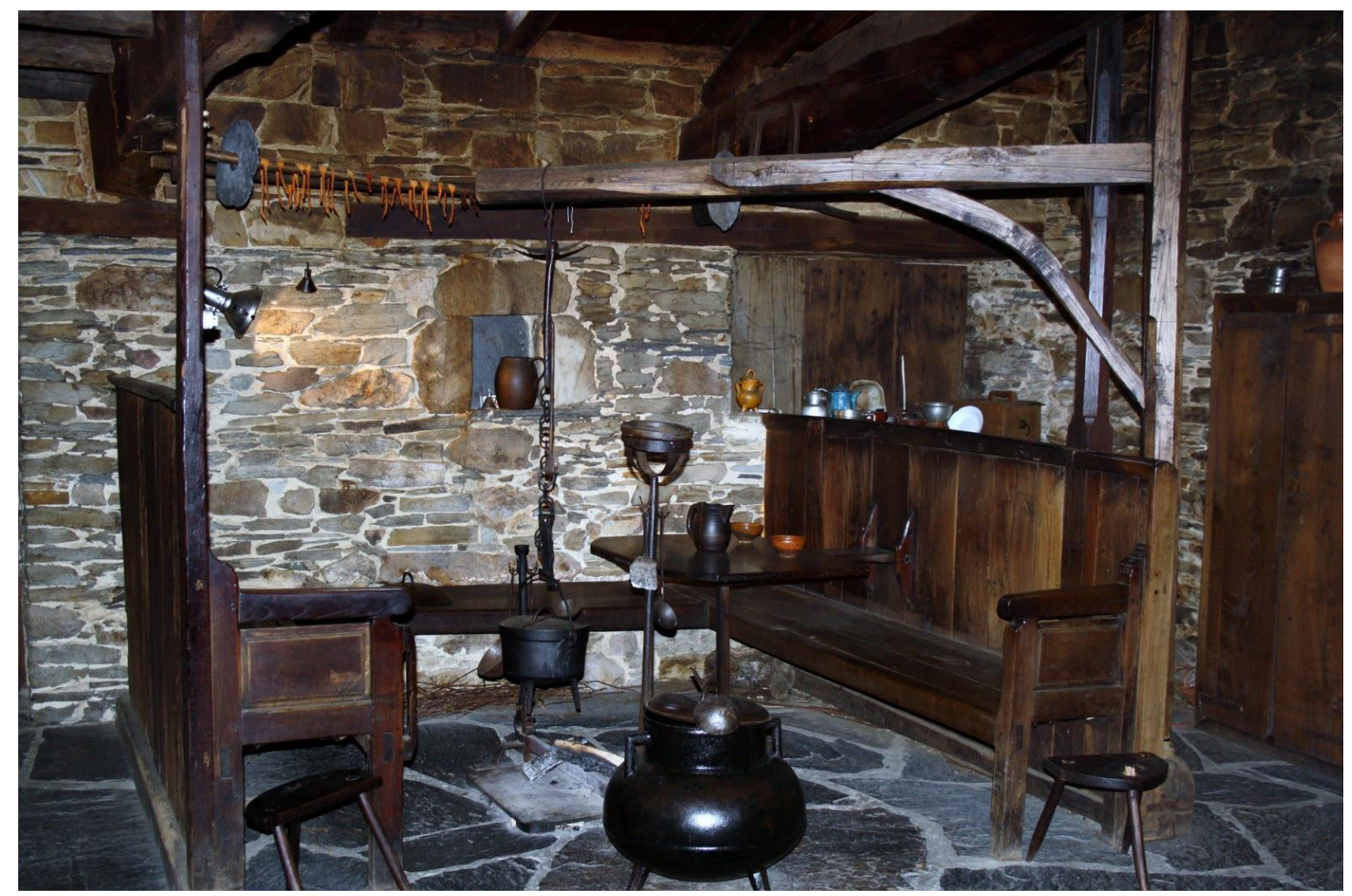

Fig. 6. Cocina del Museo-casa natal del Marqués de Sargadelos. 
La sociología del consumo ha atendido este fenómeno, y ha abierto líneas de investigación importantes a este respecto. Como ejemplo puede citarse la investigación de Araceli Serrano sobre el hogar y sus objetos ${ }^{24}$, que comienza con el siguiente párrafo:

"La casa representa mucho más que un lugar de residencia o unas estructuras físicas. Es un 'espacio-objeto' cargado emocionalmente que constituye, por una parte, un reducto de intimidad, de protección frente al 'otro' amenazante y frente a lo social y, por otra, un símbolo de status, de prestigio, de aceptación social, de diferenciación... Así, la elección de los objetos y contextos de la casa, la distribución de éstos, la segmentación de los espacios, la luminosidad, los colores, etc. son el resultado de la tensión existente entre dos dimensiones. Una primera está relacionada con procesos individuales, vinculados en mayor medida a lo emocional, a los propios miedos, definiciones, etc. y otro, ligado a procesos sociales, de inserción, prestigio y diferenciación social. Ambos polos se articulan a través de la ensoñación y de la fantasía”.

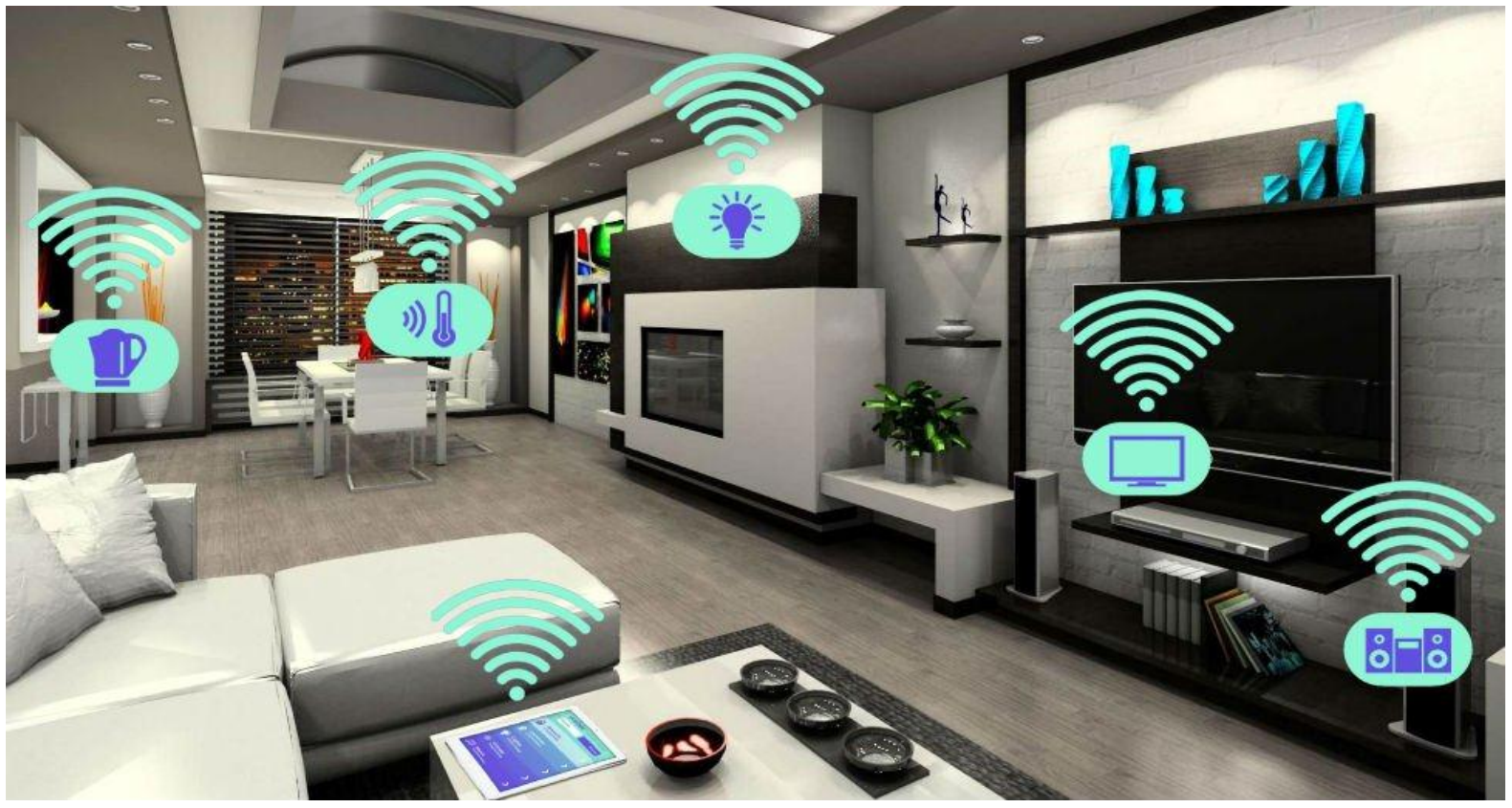

Fig. 7. Un hogar moderno con múltiples elementos tecnológicos.

La investigación de Araceli Serrano se centra en el análisis semiosociológico de la revista de decoración española Nuevo Estilo en dos momentos temporales (1978 y 1990). Dicha revista está dirigida fundamentalmente a las clases medias urbanas españolas con posibilidades de movilidad social ascendente, para tratar de orientar e influir en la decoración de las nuevas residencias urbanas y de vacaciones. El análisis de las imágenes y textos de la revista entre esas dos fechas muestra algunas tendencias importantes: desacralización de la cocina, desaparición del comedor, individualizaciónerotización del dormitorio, democratización del cuarto de estar, incremento de la mecanización, generalización de la ética postmoderna, etc. Si se hiciera un 
análisis similar hoy en día, comparando las tendencias actuales con las de hace 20 años, se podría encontrar una profundización de algunas de las tendencias, cambios en otras, y aparición de nuevas realidades. En este sentido, se puede aventurar que quizás el cambio más importante que se ha realizado en estas décadas ha sido el surgimiento del hogar en red: si a principios de los 90 pocos hogares estarían dotados de ordenadores, y mucho menos conectados a internet, hoy día la mayor parte lo están, o sino al menos la mayor parte de sus residentes a través de los teléfonos inteligentes, tabletas, ordenadores y demás tecnologías de la información y la comunicación, creando nuevas formas de relaciones sociales, que ya no son necesariamente cara a cara. Esto representa una nueva transformación de la estructura y funcionamiento de los hogares, familias y viviendas, ya que su interconexión virtual a lo largo de todo el planeta es uno de los efectos más importantes del proceso de globalización.

\section{Conclusiones}

Este breve ensayo se ha configurado como un paseo por el concepto de hogar y su importancia sociológica, examinando sus diferentes sentidos, formas y funciones. El objetivo principal ha sido ofrecer una visión de hogares, viviendas y alojamientos como motores de una demanda importantísima de amueblamiento y objetos que facilitan la vida humana y prestan servicios útiles. Al mismo tiempo, su estética es fundamental para generar un entorno agradable para la siempre difícil convivencia de los seres humanos

Thorstein Veblen, uno de los fundadores de la moderna sociología del consumo, afirma en su Teoría de la clase ociosa, después de analizar múltiples ejemplos de la realidad norteamericana, que el ocio es un reflejo de la estructura social. El hogar, la casa, la vivienda no es solo el reflejo de la estructura social, económica y de poder de una sociedad, sino su materialización a nivel microsociológico. Su estudio e investigación contribuyen a un mejor conocimiento del funcionamiento de las sociedades humanas por parte de las ciencias sociales.

\section{NOTAS}

\footnotetext{
${ }^{1}$ SILLS, David (dir.), Enciclopedia Internacional de las Ciencias Sociales, Madrid, Aguilar, 1974. Hoy en día no es posible intentar una tarea semejante, precisamente porque el enorme desarrollo científico y su especialización durante las últimas décadas hace inviable recoger un resumen completo de los avances producidos en campos tan variados como los mencionados. Además, la actual prevalencia de internet, y de herramientas como Google, Wikipedia y la gran abundancia de bases de datos y de publicaciones disponibles online, hace innecesario un esfuerzo tal para una publicación en papel como el que representó dicha Enciclopedia en su momento.

${ }^{2}$ GINER, Salvador, LAMO DE ESPINOSA, Emilio y TORRES, Cristóbal, eds., Diccionario de Sociología, Madrid, Alianza, 2006.

${ }^{3}$ ALBERDI, Inés, "Hogar" en Diccionario de Sociología, Madrid, Alianza, 2006, p. 407.

${ }^{4}$ FERNÁNDEZ ENGUITA, Mariano, "Hogar (sociología económica)” en Diccionario de Sociología, Madrid,
} 
Alianza, 2006, p. 407.

${ }^{5}$ ALBERDI, op. cit. p. 407.

${ }^{6}$ DURKHEIM, Emile, La división del trabajo social, Madrid, Akal, 1987.

${ }^{7}$ BURCKHARDT, Jacob, La cultura del Renacimiento en Italia, Madrid, EDAF, 1982.

${ }^{8}$ MARSHALL, Thomas H., Ciudadanía y clase social, Madrid, Alianza, 1998.

${ }^{9}$ Es significativo que a efectos del censo se denomina hogar al conjunto de individuos que residen habitualmente en una vivienda familiar (se equipara el número de hogares al de viviendas principales), es decir se adopta una definición de hogar como grupo de personas.

${ }^{10}$ ELIAS, Norbert, El proceso de la civilización. Investigaciones sociogenéticas y psicogenéticas, Madrid, FCE, 1993

${ }^{11}$ FREUD, Sigmund, El malestar en la cultura y otros ensayos, Madrid, Alianza, 1984

12 ELIAS, Norbert. op. cit.

${ }^{13}$ ELIAS, Norbert, op. cit, p. 460.

${ }^{14}$ FERNÁNDEZ ENGUITA, Mariano, op. cit., p. 408.

${ }^{15}$ DÍAZ, Capitolina y DEMA, Sandra, eds., Sociología y Género, Madrid, Tecnos, 2013.

${ }^{16}$ OSMOND, Marie Withers y THORNE, Barrie, "Las familias y la sociedad en la construcción social del género" en Sociología y Género, Madrid, Tecnos, 2013, pp. 127-152.

17 PARSONS, Talcott, El sistema social, Madrid, Alianza, 1982.

${ }^{18}$ OSMOND, Marie Withers y THORNE, Barrie, op. cit., p. 147.

${ }^{19}$ TORNS, Teresa y RECIO, Carolina, "La división sexual del trabajo: las desigualdades en el empleo y en el trabajo doméstico y de cuidados” en Sociología y Género, Madrid: Tecnos, 2013, pp. 153-183.

${ }^{20}$ REAL ACADEMIA ESPAÑOLA, Diccionario de la Lengua Española, Vigésima primera edición, Madrid, Espasa Calpe, 1992. A modo de anécdota, aún recuerdo mi niñez en Pola de Laviana, durante los años 50 y 60 del pasado siglo, cuando aún no estaban generalizadas las cocinas de gas o eléctricas, ni la calefacción, ni las neveras y lavadoras, y mucho menos la televisión ni internet, y la vida invernal transcurría en la mayor parte de las viviendas alrededor de la cocina de carbón que había que mantener permanentemente encendida, tanto para cocinar, calentar agua o caldear la casa.

${ }^{21}$ DURÁN, María Ángeles, "El desafío económico de las mujeres" en Sociología y Género, Madrid, Tecnos, 2013, p. 184.

${ }^{22}$ SARTI, Raffaella, Vita di casa: abitare, mangiare, vestire nell Europa moderna Roma, Laterza, 2008, p. 6, traducción del autor.

${ }^{23}$ Www.museodegrandas.com

${ }^{24}$ SERRANO, Araceli, "El hogar y sus objetos: un análisis semio-sociológico" en Política y Sociedad, n 16, Madrid, Universidad Complutense, 1994, pp. 225-231.

Fecha de recepción: 3 de diciembre de 2013

Fecha de revisión: 23 de diciembre de 2013

Fecha de aceptación: 2 de febrero de 2014 